\title{
Chronic Kidney Disease: Exploring Value-Based Healthcare as a Potential Viable Solution
}

\author{
Ellen Busink $^{d}$ Bernard Canaud ${ }^{e, f}$ Peter Schröder-Bäck ${ }^{b}$ Aggie T.G. Paulus ${ }^{a}$ \\ Silvia M.A.A. Evers ${ }^{a, c}$ Christian Apel $^{d}$ Sudhir K. Bowry ${ }^{d}$ Andrea Stopper ${ }^{g}$ \\ ${ }^{a}$ Department of Health Services Research, Care and Public Health Research Institute (CAPHRI), Maastricht University, \\ Maastricht, The Netherlands; ${ }^{b}$ Department of International Health, Care and Public Health Research Institute \\ (CAPHRI), Maastricht University, Maastricht, The Netherlands; ' Center of Economic Evaluation, Trimbos Institute, \\ Centre of Expertise on Mental Health and Addiction, Utrecht, The Netherlands; ${ }^{\mathrm{d} C e n t r e}$ of Excellence Health

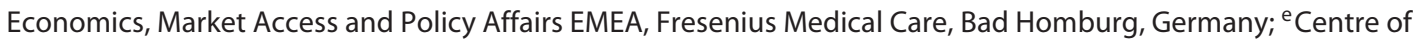 \\ Excellence Medical EMEA, Fresenius Medical Care, Bad Homburg, Germany; ${ }^{f}$ Montpellier University, School of \\ Medicine, Montpellier, France; ${ }^{9}$ Care Value Management EMEA, Fresenius Medical Care, Bad Homburg, Germany
}

\section{Keywords}

Value-based healthcare $\cdot$ Value-based renal care $\cdot$ Patient pathway · Care coordination · Benchmarking

\footnotetext{
Abstract

Background: Increasing healthcare expenditures have triggered a trend from volume to value by linking patient outcome to costs. This concept first described as value-based healthcare (VBHC) by Michael Porter is especially applicable for chronic conditions. This article aims to explore the applicability of the VBHC framework to the chronic kidney disease (CKD) care area. Methods: The 4 dimensions of VBHC (measure value; set and communicate value benchmarking; coordinate care; payment to reward value-add) were explored for the CKD care area. Available data was reviewed focusing on CKD initiatives in Europe to assess to what extent each of the 4 dimensions of VBHC have been applied in practice. $\boldsymbol{R e}$ sults: Translating VBHC into value-based renal care (VBRC) seems to be initiated to a limited extent in European health systems. In most cases not all dimensions of VBHC have been
}

utilized in the renal care initiatives. Conclusion: The translation of VBHC into VBRC is possible and even desirable if an optimal treatment pathway for CKD patients could be achieved. This would require an organizational change in health system set up and should include a strategy focusing on full care responsibility. The patient outcome perspective and health economic analysis need to be the centre of attention.

(c) 2019 S. Karger AG, Base

\section{Introduction: Value-Based Health Policy in Chronic Diseases}

The Rise of Balancing Outcome and Costs in Health Policy

Rising healthcare costs limit the sustainability of health systems worldwide. Even though health systems vary significantly on a global scale, most of them face the challenge of increasing costs [1]. In Europe, for instance, increased healthcare spendings are not necessarily corre- (c) 2019 S. Karger AG, Basel

E-Mail karger@karger.com

www.karger.com/bpu
Ellen Busink

Fresenius Medical Care EMEA

Centre of Excellence Health Economics, Market Access and Policy Affairs

Else Kroener Strasse 1, DE-61352 Bad Homburg (Germany)

E-Mail Ellen.Busink@fmc-ag.com 
lated with improved patient outcomes [2]. Cost drivers of healthcare are mainly related to demographic indicators, medical needs, technological advancements, treatment availability and accessibility, increased earnings of the general population, inadequate care set-ups and health system inefficiency in comparison to other sectors [2]. Another cost driver is the commonly used fee-for-service reimbursement model, in which the delivery of "unnecessary care" is a highly contentious issue as physicians/clinics/hospitals or practices might be inclined to deliver more care than might be required for optimized patient outcomes [3]. Finally, fragmented care tends to increase redundancy of points of care especially between primary and secondary care automatically adding costs through the fee-for-service scheme [4]. A redesign of healthcare delivery systems with a focus primarily on preventive care, including patient engagement, has been proposed to address the aforementioned issues [5]. In particular, health systems that are primarily focused on acute instead of chronic care incentivize siloed treatment episodes, a shift to continuous integrated pay-for-performance care should be promoted $[4,6]$.

Over the past decades there have been numerous policy attempts to improve health systems' performance by determining the right balance between optimal treatment outcome and total spending. Sustainable total cost reduction was rarely achieved, often resulting in mere cost shifting from one disease area or provider to another [7]. Short-term savings are frequently documented, but only as a result from rationing or cost shifting towards other stakeholders including the patient (i.e., in the form of copayments) [7]. These lead in the end to long-term detrimental effects, with patients more frequently utilizing emergency unplanned care, for example, Emergency Room hospital visits, offsetting even higher costs as such visits are unpredictable [7].

One particular good example of a possible health system redesign is integrated care. Integrated care focuses on reducing the fragmentation of care, thereby improving outcomes for chronic patients by coordinating care providers along a patient's pathway [8]. The source for the development of integrated care is the Triple Aim model developed by the Institute for Healthcare Improvement [9]. The framework describes 3 dimensions to address current health system challenges through (1) improving patient experience of care, (2) improving a population's health status, and (3) reducing total costs [9].

Another example is the framework developed by Chassin et al. [10] to assess the underlying causes of low-quality care in the United States by overuse, underuse and misuse of healthcare services. Two major changes are proposed to reduce this (1) medical education and training and (2) healthcare delivery system change [10]. Since then, Chassin and Loeb [11] especially reviewed the second change in more detail for hospital operations by using the principle of "high reliability". Three major requirements for achieving high reliability are leadership, integrating a safety culture and a robust process improvement [11]. Similarly to integrated care it highlights the importance of breaking the "pockets of excellence" practice and moving to more coordinated care delivery [12].

\section{Aim: Translating Value-Based Healthcare into \\ Value-Based Renal Care}

This paper explores the case of applying value-based healthcare (VBHC) to a specific chronic disease area - the renal field - and discusses its translation into "valuebased renal care" (VBRC).

Kidneys have as a vital function maintaining health by clearing the body of both excess fluids and toxins that are unwanted by-products of metabolism [13]. Additionally, the kidneys produce hormones that help to regulate blood pressure and other essential physiological processes. A gradual loss of kidney function over time is a condition commonly known as chronic kidney disease (CKD). The severity of CKD is expressed by 5 stages, typically defined by the assessment of the glomerular filtration rate (GFR) [14]. A decreased GFR is associated with an increased risk of death, cardiovascular events, and overall hospitalizations [15]. The early CKD stages often go undetected but at CKD stage 3, patients present with health complications often requiring costly unplanned inpatient care [16].

The typical CKD (stage 3-5) patient today is 65 years or older, presents with multiple co-morbid conditions such as hypertension and/or diabetes, having a pill burden of on average 11 medications per day and is hospitalized for 6-11 days per year [17-23]. Therefore, the treatment of CKD patients represents a substantial economic burden to health systems, especially when patients acquire the end-stage kidney disease (ESKD) [24, 25]. At the same time, the patient's quality of life, mortality and morbidity is significantly and adversely affected $[15,26]$.

A patient reaching a GFR of $<15 \mathrm{~mL} / \mathrm{min} / 1.73 \mathrm{~m}^{2}$ (stage 5) has reached ESKD requiring costly, life-saving renal replacement therapy (RRT) such as transplantation (Tx) or dialysis [14]. RRT has a global patient population of $0.15 \%$ but consumes $2-4 \%$ of health systems' healthcare budget [24].

VBHC could offer opportunities to provide care for these patients more cost effectively. The aim of translat- 
Fig. 1. Schematic overview of the 4 essential components of VBHC [28].



ing VBHC into VBRC should be to holistically address the full patient pathway from prevention or delay of renal progression to end-of-life care. To investigate the transferability of such a framework, the article is structured to describe the burden of CKD and current therapy pathways that are utilized and finally reviews the applicability of defined VBHC components within the renal field.

\section{Theory: The VBHC Framework}

One of the health policy frameworks to integrated care that aims to involve all stakeholders (patients, payers, providers, policymakers) is VBHC [27]. The concept of VBHC has entered the arena of health policy debates, proposing a framework that facilitates rigorous change required as described above. VBHC is a concept introduced by Michael E. Porter and Elizabeth O. Teisberg in: Redefining Healthcare, Creating Value-Based Competition on Results (2004), to organize healthcare based on meaningful outcomes to patients and maximizing value delivered [28]. Value in this context "is defined as the health outcomes achieved per dollar spent" [5]. This notion has been essentially developed for the American health system but has also been taken up and adapted to the European setting, for example, in Germany, Sweden and the United Kingdom [29, 30]. European health systems differ significantly in terms of funding, financing, principles of care delivery and so on. Therefore, VBHC applicability in Europe would have to be analyzed for each health system individually [31]. Nevertheless, one of the areas where the VBHC concept could particularly be relevant is for chronic disease management, with a rapidly increasing number of patients as well as costs where the scarcity of healthcare delivery has become most notable [32]. Expanding patient populations requiring continuous care with the same or even shrinking healthcare budget could benefit most from a health system organiza- tion that strives for high-quality care while containing costs [2].

The key construct of VBHC is to create a value environment where long-term outcome for all stakeholders is improved while total costs are contained [28]. The essential components for creating a value-based healthcare service system can be summarized as follows: (1) measure outcomes meaningful for patients and associated costs accurately by medical condition, (2) communicate these outcomes and costs transparently with a performance classification ("benchmarking"), (3) organize coordinated care relying on multidisciplinary teams around a patient's medical profile, and (4) develop innovative (bundled) payment schemes to foster joint outcome responsibility and selectively reward high-performing care providers accordingly (Fig. 1) [28]. These components should reflect the full care cycle or for chronic conditions should ideally cover the complete patient pathway but should at least reflect a time period of 1 year or more [28]. In the following section, the key components of VBHC are portrayed in the context of the renal care setting.

\section{Applying the VBHC Framework to the Renal Setting}

A literature review was conducted to identify available data on the implementation of VBHC into renal care. Below the rationale of using the 4 key components of $\mathrm{VBHC}$ in the renal setting and some examples of initiatives in the renal care area are described.

\section{Measure Value}

To measure value accurately, all required services including equipment, personnel, infrastructure and so on, over a relevant time period need to be considered [28]. Value is ultimately determined by outcomes meaningful to patients and associated costs that best reflect their medical condition including all associated co-morbidities 
Fig. 2. ICHOM CKD standard set (b) [37] applied to prioritization in outcome measures (adapted from Porter's outcome measures hierarchy; a) [28]. HRQoL, health related quality of life; PD, peritoneal dialysis.

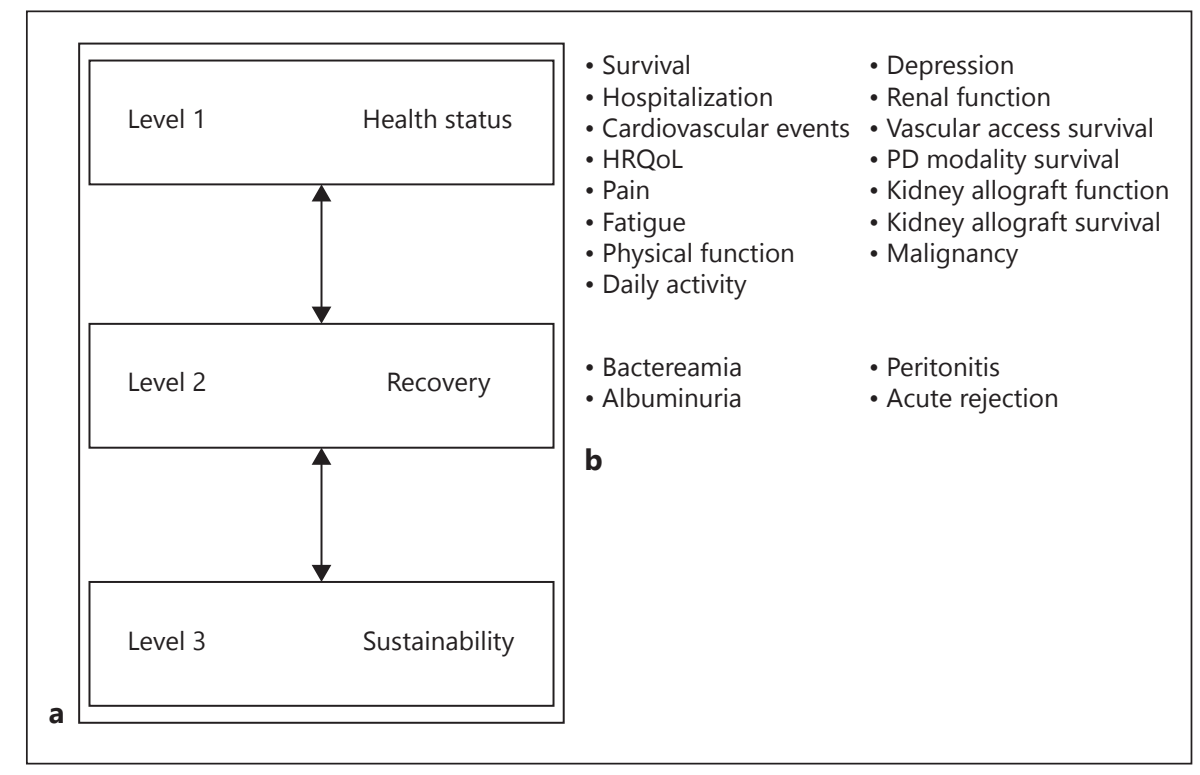

[28]. The recommended methods for measuring patient outcomes and costs are described in the next section, including example parameters that are used or could be used specifically for patients with CKD/ESKD.

\section{Measure Outcomes Meaningful to Patients}

To identify the "meaningful outcomes" Porter developed the "Outcome Measures Hierarchy" to structure outcomes according to importance, short- and long-term impact and risk factors for achieving these [28]. The hierarchy is 3-tiered and with 2 levels in each tier, the first tier represents the most important outcomes, that is, mortality/quality of life [28]. Outcome dimensions stated in subsequent tiers gradually reduce in terms of priority (Fig. 2).

As part of identifying these meaningful outcomes, the Harvard Business School together with the Karolinska Institute and the Boston Consulting Group established the International Consortium for Health Outcome Measurements (ICHOM) [33]. This consortium brings together stakeholders (including patients) from around the world for a particular disease area to define and prioritize adequate outcome measures [34]. The aim of this consortium was to define and publish standard outcome sets covering more than $50 \%$ of the global disease burden by 2017 [35]. This mission was achieved and even superseded, with 54\% of the global disease burden covered in the respective timeframe [35]. These standard outcome sets are to be used across the world to allow benchmarking and uniformly influence care standards [36]. CKD has been selected as one of the disease areas for standard outcome set development. The set has recently been published [37] (Fig. 2).

The challenge will now be the implementation and to have these measures systematically applied by healthcare providers across health systems, as there is currently a high variability in measurements of CKD patient outcomes [38]. Particularly, in current practice more laboratory and clinical performance indicators are collected instead of patient relevant outcomes, including patient reported outcome measures (PROMs) [38]. Nevertheless, some forerunners of health-related quality-of-life measurements in renal care can be found in practice. For example, in the Netherlands, a pilot has recently started to measure PROMS and patient reported experience measures. Within this pilot, the process of filling up a questionnaire will be conducted twice a year in $\sim 40$ dialysis clinics [39].

Next to the publication of the CKD, a standard set of other initiatives have been commenced worldwide including the QUality European Studies, the Chief Medical Officers, and the Standardized Outcomes in Nephrology initiative [40-42]. Even though the Standardized Outcomes in Nephrology initiative was set out to define a standard set of outcomes to be measured in clinical trials, the results could be considered for other applications in real-world practice as well.

\section{Measure Costs Meaningful to Health Systems}

To put the meaningful patient outcomes into perspective, a cost element has been included in the VBHC framework. It is therefore of utmost importance to measure 
treatment items separately budgeted to capture a realistic cost calculation of a patient's care cycle [43]. Cost as a measurement has many different interpretations in healthcare and is often confused with reimbursement rates, or what is charged to health insurance [43]. In the current health system settings, 2 major problems are identified: (1) the cost-aggregation problem and (2) the cost-allocation problem [43]. First, the distribution of costs is challenging to monitor accurately leading to incomplete economic evaluations, misrepresenting all costs borne by a health system/patient [43]. Second, due to this challenge of monitoring costs accurately, usually an average consumption is calculated instead of the actual resources used [43]. Therefore, currently in many health systems, no accurate measurement of costs can be made for a patient's medical condition.

The challenges described above are no different in the renal care field, especially as there are many pathways a patient can choose depending on the progression of the disease [44]. As mentioned in the introduction, CKD has 5 stages, with a higher care requirement from stage 3 onwards $[44,45]$. In particular, hospitalization and medication utilization increase significantly due to a higher incidence of cardiovascular events associated with renal progression $[15,23]$.

As soon as a patient has reached stage 5 , preparations for RRT are made where a patient is provided with 4 options: kidney $\mathrm{Tx}$, peritoneal dialysis, haemodialysis, or end-of-life/conservative care [24]. Patients are usually faced with this decision more than once in their life, as patients frequently require switching between certain modalities for a variety of reasons [46]. This makes it particularly difficult to track costs accurately as the cost drivers come from different sources and are provided by different healthcare professionals [47]. Applying Porter's model to a CKD patient would entail to track meaningful disease-specific costs from a patient entering CKD stage 3 until death [48]. To the authors' knowledge, such a cost mapping exercise along a CKD patient's pathway has never been performed. The aforementioned exercise would entail but is not limited to measuring costs of transitioning between different care modalities, transportation, productivity loss, premature death, informal care, psychological support, sick leave and so on [49].

Set and Communicate Value Transparently with a Performance Classification ("Benchmarking")

As a next step, the outcomes and costs would not only be measured accurately but have to be communicated transparently and understandably to all stakeholders involved (i.e., patients, payers and providers) [43]. Such communication should be phased in carefully, but once fully implemented, a performance classification can be attached to the outcomes achieved by individual providers [28]. This so-called benchmarking allows providers and payers to compare and motivate for improvement across a health system through different payment schemes [28]. There are a variety of methods by which such values could be published; 1 good example is the use of registries for outcome reporting as part of real-world evidence data collection [50]. A registry in the medical field can be used for a variety of purposes, in VBHC for the evaluation of medical practice the term "patient registry" is often used [50]. A patient registry uses observational research methods for data collection to support clinical/economic and/ or policy decision making [50]. Such registries lead to increased transparency of clinical practice particularly also for the patient. A good example is the "health map" in the Netherlands, an online database accessible to the public where a provider is ranked in terms of their clinical and patient experience performance for specific disease areas [51]. Such a tool that incorporates registry data, increases outcome transparency within a healthcare delivery system and consequently introduces an element of benchmarking towards providers [52].

For CKD specifically, the European Renal Association - European Dialysis and Tx Association (ERA-EDTA) registry is a well-known example [53]. Data that is currently obtained through this registry include cause of renal failure, co-morbidity status, cause of death and so on [54]. A comparison of the outcomes currently measured by ERA-EDTA and the outcome measures suggested by ICHOM are depicted in Table $1[37,54]$. As can be seen Table 1 , there is already an overlap in outcomes measured and proposed. The main differentiation between ICHOM and ERA-EDTA is the PROMs and patient reported experience measures. Therefore, the ERA-EDTA registry offers a great opportunity for adding certain parameters to this platform, while having already cross-national information available [50] (Table 1).

\section{Organize Coordinated Care Relying on \\ Multidisciplinary Teams around a Patient's Medical Profile}

One important component of VBHC is to deliver tailor-made care to each individual patient, based on demographics, clinical indicators, co-morbidities, location and timing [28]. Supporting in such personalized care are evidence-based clinical practice guidelines implemented 
Table 1. Aligning the outcomes measured in ERA-EDTA registry and proposed outcomes to be measured by ICHOM $[37,54]$

\begin{tabular}{|c|c|c|c|}
\hline Group & Outcomes & & ICHOM \\
\hline Demographics & $\begin{array}{l}\text { Date of birth } \\
\text { Gender } \\
\text { Education level }\end{array}$ & $\begin{array}{l}\mathrm{X} \\
\mathrm{X}\end{array}$ & $\begin{array}{l}X \\
X \\
X\end{array}$ \\
\hline $\begin{array}{l}\text { Baseline } \\
\text { Characteristics }\end{array}$ & \begin{tabular}{l} 
Smoking status \\
Nutritional status \\
Co-morbidities \\
Date of start first RRT \\
Cause of renal failure \\
Treatment center \\
Primary renal disease \\
Previous treatment(s) \\
Previous graft \\
Type of vascular access \\
Type of transplant: \\
\multicolumn{1}{c}{ deceased/living donor }
\end{tabular} & $\begin{array}{l}X \\
X \\
X \\
X \\
X \\
X\end{array}$ & $\begin{array}{l}X \\
X \\
X \\
X \\
X\end{array}$ \\
\hline $\begin{array}{l}\text { Burden of } \\
\text { Care }\end{array}$ & $\begin{array}{l}\text { Survival } \\
\text { Date and cause of death } \\
\text { Hospitalization } \\
\text { Cardiovascular events }\end{array}$ & $\begin{array}{l}X \\
X\end{array}$ & $\begin{array}{l}X \\
X \\
X\end{array}$ \\
\hline $\begin{array}{l}\text { Health and } \\
\text { Wellbeing }\end{array}$ & $\begin{array}{l}\text { HRQoL } \\
\text { Pain } \\
\text { Fatigue } \\
\text { Physical function } \\
\text { Depression } \\
\text { Daily activity }\end{array}$ & & $\begin{array}{l}X \\
X \\
X \\
X \\
X \\
X\end{array}$ \\
\hline $\begin{array}{l}\text { Treatment } \\
\text { Specific }\end{array}$ & $\begin{array}{l}\text { Renal function } \\
\text { Vascular access survival } \\
\text { PD modality survival } \\
\text { Malignancy } \\
\text { Kidney allograft function } \\
\text { Kidney allograft survival } \\
\text { Acute rejection } \\
\text { Albuminuria } \\
\text { Bacteraemia } \\
\text { Peritonitis }\end{array}$ & & $\begin{array}{l}X \\
X \\
X \\
X \\
X \\
X \\
X \\
X \\
X \\
X\end{array}$ \\
\hline
\end{tabular}

ERA-EDTA, European renal association-European dialysis and transplantation association; ICHOM, international consortium for health outcome measurement; RRT, renal replacement therapy; HRQoL, health related quality of life.

for many disease areas. For CKD, a good example is the ERA-EDTA European Renal Best Practice guidelines [55]. These guidelines provide a highly standardized basis for treating patients with CKD and the different pathways a patient can take when RRT is required. However, this well-established standardized basis is not always applied in practice. The Dialysis Outcome and Practice Patterns Study highlights some of these standards of practice gaps, for example, comparing Russia to other European countries [56]. This is a great example of how measuring value could promote patient care improvement by reviewing and implementing best practices across Europe.

Next to best practice exchange, care coordination is one of the central elements for VBRC by organizing a patient's care cycle with a multidisciplinary care team [28]. Such a team would review a patient's medical profile to determine an integrative therapy plan (including treatment choice and start) involving all relevant medical experts [28]. Additionally a multidisciplinary team would ensure not only improved care continuity but also an enhanced patient/family engagement along the entire pathway when properly set up [57]. A patient in this structure could, for example, be empowered by a care manager who motivates and educates patients to achieve optimal treatment outcomes [57]. In particular, for chronic diseases, this is essential, where evidence clearly shows that continuity and patient engagement are 2 main sources for improved therapy adherence [57]. Specifically for CKD patients the integrative aspect is essential, as a variety of caregivers are involved: (1) due to the health system set up (a CKD patient is first usually seen by a general practitioner before co-treatment with a nephrologist is established), (2) the high pill burden for a patient and (3) the majority of CKD patients have co-morbidities and are being treated by other care providers than nephrologists $[20,23,58]$. Additionally, as a CKD patient will be on different treatment options in their life, it is therefore crucial to determine the right modality for the right patient at the right time in the right location [46]. Care coordination for CKD patients has already been introduced in the US health system, and some pilots have also been introduced in the European setting $[59,60]$. The extension of such pilots to standard of care would entail to put patients in the centre of care provision and decision making, organizing across disciplines accordingly [60]. Moreover, such a set up would enable a care delivery system to follow a patient through the care cycle carefully to then measure and communicate meaningful outcomes and resource utilization accurately [28].

\section{Exploring Payment Models to Reward Value-Add}

As a last component of the VBHC model, the total added value that is created through the first 3 building blocks should be rewarded to those who follow and achieve the relevant patient outcomes defined [28]. The development of a bundled payment to foster joint outcome responsibility and reward providers that achieve pre-defined patient outcomes is the last step in the VBHC framework [28]. 


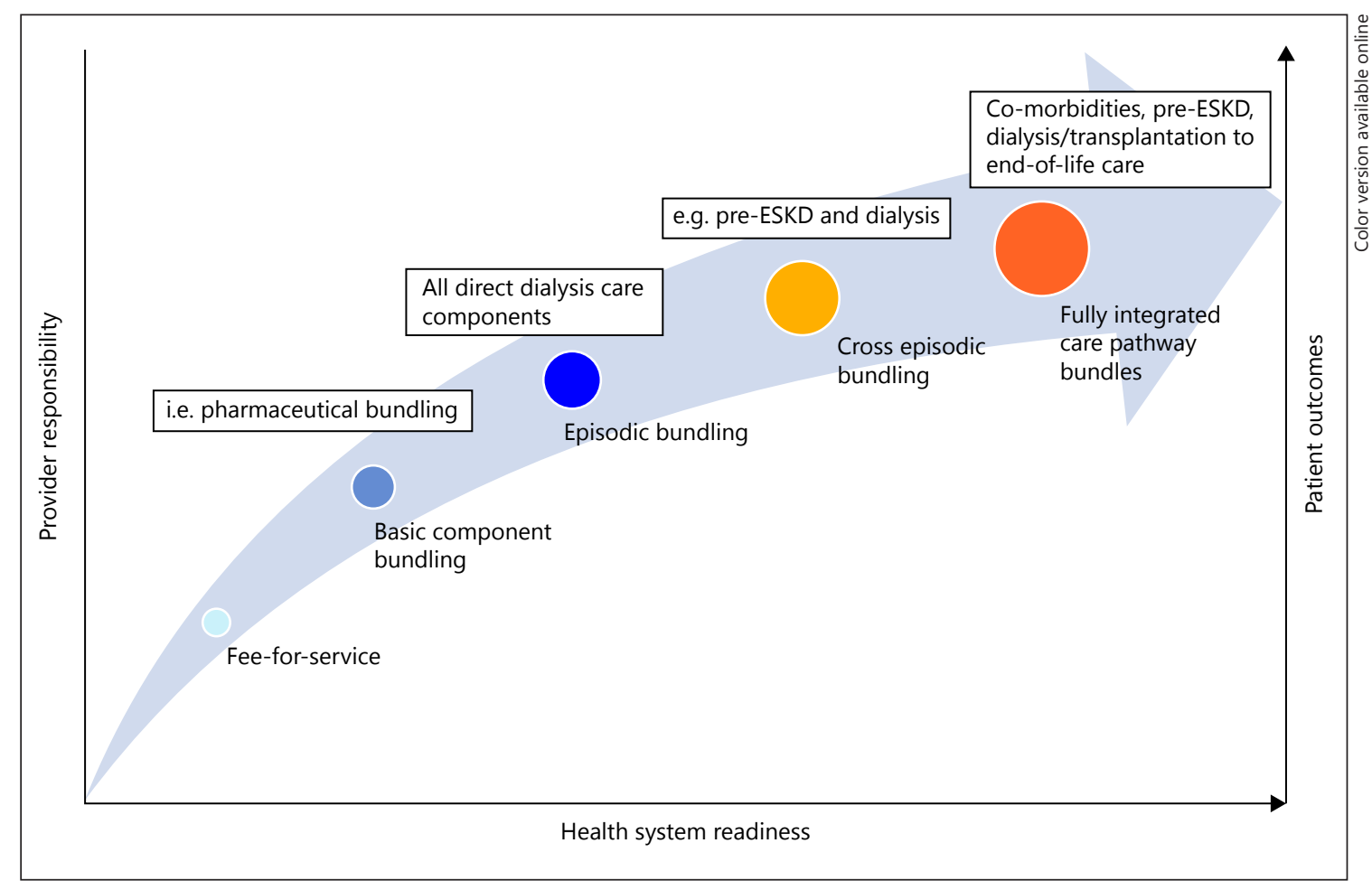

Fig. 3. Porter's bundling framework applied to the renal care setting. ESKD, end-stage kidney disease.

Among existing options, bundling has been proposed by Porter as the most suitable scheme for such rewards, which entails that providers are reimbursed for the care responsibility of certain elements of the patient care cycle (that may include services, procedures, tests, drugs, and devices) [27]. In bundling, different degrees of responsibility/complexity are offered: (1) basic component bundling, (2) episodic bundling, (3) cross episodic bundling and (4) fully integrated care pathway bundling [27]. Figure 3 contains the detailed information on the level of provider integration/responsibility, moving from simple to complex [61].

Next to the different levels of service bundling, a payment scheme can be introduced to make providers accountable and reward/penalize their performance on treatment outcomes accordingly [62, 63]. Often such structures are introduced alongside service bundling to ensure that outcome quality is not compromised for total cost containment [62]. The most commonly used schemes include (1) pay-for-performance, which is a model that consists of a financial incentive based on a provider's ability (or inability) to meet certain key performance indicators [62]. (2) Shared Savings/Risk-Sharing Methods, where providers and payers enter into an agreement that holds them collectively responsible for the total expense of a given patient population, by rewarding or possibly penalizing providers for their spending performance [62]. (3) Lastly, Gain Sharing that is a joint strategy of the payer and provider to increase focus on cost containment, while improving patient outcomes through an encouragement of integrated care models (final step in bundling continuum) [63].

In renal care, such value-based payments have already been applied in the United States and even in some European countries. In Portugal, for example, the Ministry of Health in 2008 took initiatives to strengthen its health system sustainability by introducing a bundling scheme with pre-defined key performance indicators, termed "Comprehensive Price Payment" [64].

The service bundle includes almost all components of a dialysis care episode. In 2014, a quality assessment following the introduction of the bundling scheme was conducted. Despite an increase of 3\% of the haemodialysis population, a marked reduction in mortality and hospitalization rate was observed [65]. Moreover, patients felt more adequately informed about their treatment, which is positively related to a higher level of patient empowerment [65]. From a cost perspective, the bundle showed a 
significant health system gain, and apart from a pre-arranged $14.3 \%$ reimbursement cut, a $10.5 \%$ total cost saving was observed mainly due to a reduction in unplanned hospitalization [64]. By shifting more care responsibility to the provider, a fair chance was given to find efficiencies along the treatment pathway without compromising patient outcome [65].

Therefore, value-based payments are not unfamiliar in the European setting. However, to the best of our knowledge, these schemes do not (yet) focus on the most holistic approach; of a fully integrated pathway from (1) prevention/delay of RRT to (2) transition management to the (3) right RRT therapy for the right patient at the right time [24]. The bundle schemes and outcome accountability methods for CKD/ESKD have so far to the author's knowledge been focused on the first 2 stages of bundling and have not yet progressed to the fully integrated care pathway bundle. Ultimately, this should be the goal of a VBRC Model, with a higher investment in personalized and preventative measures for RRT [28].

\section{Discussion/Conclusion}

The exploratory literature analysis of the VBHC framework being transferred into VBRC reveals relevance and the potential to provide patient-centric care while achieving cost-effective and societal value. A successful shift from current standard of care to VBRC requires a stepby-step approach from simple to complex, driven by a joint collaboration of patients, health authorities, payers, and providers [28]. A clear evidence-based guideline on the 4 components described in section 2 needs to be developed for the renal setting and systematically implemented.

Additionally, a priority shift from treatment to preventive measures needs to be integrated with a more individualized pathway considering the patient perspective/choice, timing and suitable therapy modality [46]. Setting this up in combination with a payment scheme including a risk-sharing or shared saving component seems the most beneficial for all stakeholders involved [27].

Simultaneously, a strategy to move from the current fragmented care to assigning full accountability of a CKD patient to one stakeholder that would coordinate with all other parties involved has to be investigated. The following steps could be a pathway as part of this strategy by: (1) defining the optimal CKD patient pathway based on meaningful patient outcomes, from early screening to end-of-life care ("the right patient for the right modality at the right time in the right location") [46]. This would, for example, include the optimal timing to initiate preparation for transitioning to RRT, especially relating to dialysis access creation. (2) After determining this pathway, mapping the CKD patient care cycle to estimate the associated costs. Insights into the expenditure on the complete CKD patient pathway could reveal cost drivers for potential efficiency gains. (3) Assessing whether such an approach would be cost effective from a health economic perspective and if not, what ethical implications might play a role (e.g., anaemia management). (4) Outlining a sustainable VBRC set up that has to be embedded in health policy and finally to (5) detect provider profiles that could successfully adopt and therefore be rewarded for the implementation of VBRC.

As with other health policy initiatives, they can only be successful when being implemented systematically. For example, Valentijn et al. [67] and Jones et al. [66] conducted an analysis to explore the applicability of the integrated care model and future strategies for implementation in the renal care setting. Their main conclusion was that some pilots were initiated, but the process changes in standard of care have so far been on a rather small scale, instead of on a meaningful level $[66,67]$. A similar conclusion can be drawn for the Chassin and Loeb [12] assessment on improving quality of care in particular in hospitals.

The biggest change that would have to be made for VBRC is a restructuring of the health system's organizational set up to harmonize outcome measures, data collection, collaboration of providers for the different points of care and to financially incentivize those that are successful at changing to this set up. This could lead to achieving an optimal patient pathway for renal patients focusing on full care responsibility. The patient outcome perspective and health economic analysis needs to be at all times the centre of attention.

\section{Disclosure Statement}

E.B., B.C., C.A., S.K.B., and A.S. would like to declare employment at Fresenius Medical Care Deutschland $\mathrm{GmbH}$ the world leading provider of products and services for people with chronic kidney failure. The authors have no other relevant affiliations or financial involvement with any organization or entity with a financial interest in or financial conflict with the subject matter or materials discussed in the manuscript apart from those disclosed. No writing assistance was utilized in the production of this manuscript. The results presented in this paper have not been published previously. 


\section{References}

12016 Global Health Care Outlook: Battling Costs While Improving Care. https://www2. deloitte.com/Health-Care/gx-lshc2016-health-care-outlook.pdf: Deloitte, 2016.

2 Marino A, Morgan D, Lorenzoni L, James C: Future Trends in Health Care Expenditure: A Modelling Framework for Cross-Country Forecasts, 2017, Report No: 1815-2015.

3 Jacobs R, Honoré PM, Bagshaw SM, Diltoer M, Spapen HD: Citrate formulation determines filter lifespan during continuous venovenous hemofiltration: a prospective cohort study. Blood Purif 2015;40:194-202.

4 Nolte E, Knai C, Saltman RB: Assessing Chronic Disease Management in Europe. http://www.euro.who.int/_data/assets/pdf_ file/0010/277939/Assessing-chronic-diseasemanagement.pdf?ua=1: European Observatory on Health Systems and Policies, 2014.

5 Porter ME, Teisberg EO: Redefining Health Care: Creating Value-Based Competition on Results. Boston, Harvard Business School Press, 2006.

6 Desmedt M, Vertriest S, Hellings J, Bergs J, Dessers E, Vankrunkelsven P, et al: Economic impact of integrated care models for patients with chronic diseases: a systematic review. Value Health 2016;19:892-902.

7 Porter ME, Teisberg EO: Redefining competition in health care. Harv Bus Rev 2004;82:12.

8 Tsiachristas A, Stein V, Evers S, Rutten-vanMoelken M: Economic Evaluation of Integrated Care: A Research Agenda. Health Economics Special Interest Group; International Foundation for Integrated Care, 2016.

9 Berwick DM, Nolan TW, Whittington J: The triple aim: care, health, and cost. Health Aff (Millwood) 2008;27:759-769.

10 Chassin MR: Is health care ready for six sigma quality? Milbank Q 1998;76:27.

11 Chassin MR, Loeb JM: High-reliability health care: getting there from here. Milbank Q 2013; 91:32.

12 Chassin MR, Loeb JM: The ongoing quality improvement journey: next stop, high reliability. Health Aff (Millwood) 2011;30:559568.

13 National Institute of Health (NIH): The Kidneys and How They Work. https://www.niddk.nih.gov/-/media/Files/Kidney-Disease/ yourkidneys_508.pdf?la, 2014.

14 National Kidney Foundation: K/DOQI clinical practice guidelines for chronic kidney disease: evaluation, classification, and stratification. Am J Kidney Dis 2002;39(2 suppl 1):S1S266.

15 Go AS, Chertow GM, Fan D, McCulloch CE, Hsu C: Chronic kidney disease and the risks of death, cardiovascular events, and hospitalization. N Engl J Med 2004;351:1296-1305.

16 Lonnemann G, Duttlinger J, Hohmann D, Hickstein L, Reichel H: Timely referral to outpatient nephrology care slows progression and reduces treatment costs of chronic kidney diseases. Kidney Int Rep 2017;2:142-151.
17 European Renal Care Provider Association: CKD Facts \& Figures. http://ercpa.eu/index. php/facts-figures/, 2016.

18 Chen YR, Yang Y, Wang SC, Chiu PF, Chou WY, Lin CY, et al: Effectiveness of multidisciplinary care for chronic kidney disease in Taiwan: a 3-year prospective cohort study. Nephrol Dial Transplant 2013;28:671-682.

19 Eriksson JK, Neovius M, Jacobson SH, Elinder CG, Hylander B: Healthcare costs in chronic kidney disease and renal replacement therapy: a population-based cohort study in Sweden. BMJ Open 2016;6:e012062.

20 Fraser SD, Roderick PJ, May CR, McIntyre N, McIntyre C, Fluck RJ, et al: The burden of comorbidity in people with chronic kidney disease stage 3: a cohort study. BMC Nephrol 2015;16:193.

21 Pinho NA, Silva GV, Pierin AM: Prevalence and factors associated with chronic kidney disease among hospitalized patients in a university hospital in the city of São Paulo, SP, Brazil. J Bras Nefrol 2015;37:91-97.

22 Schneider KM, O’Donnell BE, Dean D: Prevalence of multiple chronic conditions in the United States' Medicare population. Health Qual Life Outcomes 2009;7:82.

23 Wee HL, Seng BJ, Lee JJ, Chong KJ, Tyagi P, Vathsala A, et al: Association of anemia and mineral and bone disorder with health-related quality of life in Asian pre-dialysis patients. Health Qual Life Outcomes 2016;14:94.

24 Vanholder R, Annemans L, Brown E, Gansevoort R, Gout-Zwart JJ, Lameire N, et al: Reducing the costs of chronic kidney disease while delivering quality health care: a call to action. Nat Rev Nephrol 2017;13:393-409.

25 Yang M, Fox CH, Vassalotti J, Choi M: Complications of progression of CKD. Adv Chronic Kidney Dis 2011;18:400-405.

26 Kent S, Schlackow I, Lozano-Kühne J, Reith C, Emberson J, Haynes R, et al: What is the impact of chronic kidney disease stage and cardiovascular disease on the annual cost of hospital care in moderate-to-severe kidney disease? BMC Nephrol 2015;16:65.

27 Porter ME, Kaplan RS: How to pay for health care. Harv Bus Rev 2016;94:88-98,100,134.

28 Porter ME: What is value in health care? $\mathrm{N}$ Engl J Med 2010;363:2477-2481.

29 Porter ME, Guth C: Redefining German Health Care: Moving to a Value-Based System. Heidelberg, Springer-Verlag, 2012, p 308.

30 The Economist Intelligence Unit: ValueBased Healthcare: A Global Assessment, 2016. http://vbhcglobalassessment.eiu.com/ value-based-healthcare-a-global-assessment/ ( September 3, 2017).

31 The Economist Intelligence Unit: Value-based Healthcare in Europe: Laying the Foundation, 2016. http://perspectives.eiu.com/healthcare/ value-based-healthcare-europe-laying-foundation/white-paper/value-based-healthcareeurope-laying-foundation? redirect=TRUE.
32 Elsevier Clinical Solutions: White Paper: Improved Chronic Disease Management with Alternative Healthcare Delivery, 2015. https://www.elsevier.com/_data/assets/pdf file/0007/162592/Chronic-Disease-WhitePaper-0-2.pdf.

33 International Consortium of Health Outcome Measures (ICHOM). Who We Are, 2017. http://www.ichom.org/who-we-are/. http://www.ichom.org/who-we-are/(August 16, 2017).

34 International Consortium of Health Outcome Measures (ICHOM). How We Work, 2017. http://www.ichom.org/how-we-work/ (October 11, 2017).

35 International Consortium of Health Outcome Measures (ICHOM). Medical Conditions, 2017. http://www.ichom.org/medicalconditions/(August 16, 2017).

36 ICoHOM: About Standard Sets, 2018. https:// www.ichom.org/standard-sets/\#about-standard-sets (October 28, 2018).

37 International Consortium of Health Outcome Measures (ICHOM). Chronic Kidney Disease, 2017. http://www.ichom.org/medical-conditions/chronic-kidney-disease/ (Febraury 11, 2018).

38 Nistor I, Bolignano D, Haller MC, Nagler E, van der Veer SN, Jager K, et al: Why creating standardized core outcome sets for chronic kidney disease will improve clinical practice. Nephrol Dial Transplant 2017;32:1268-1273.

39 Nefrovisie. PROMs en PREMs: Patiënten Aan Het Woord Over Kwaliteit, 2017. http://www. nefrovisie.nl/nieuwsbrief-uitgelicht-artikel/ proms-en-prems-patienten-aan-het-woordover-kwaliteit/(August 16, 2017).

40 Standardized Outcomes in Nephrology (SONG), 2018. http://songinitiative.org.

41 The CMO Initiative: Improving the Continuity of Care for Dialysis Patients, 2018. https:// www.healio.com/nephrology/policy-andpolitics/news/online/\%7B41fd5fc4-8e194b6a-8d85-6b972762a2a7\%7D/the-cmo-initiative-improving-the-continuity-of-carefor-dialysis-patients.

42 Jager KJ, Zoccali C: QUality European STudies (QUEST) - a step forward in the quality of RRT care. Nephrol Dial Transplant 2005;20: 2005-2016.

43 Porter ME: What is value in health care? N Engl J Med 2010;363:Supplementary Appendix 1.

44 Braun L, Sood V, Hogue S, Lieberman B, Copley-Merriman C: High burden and unmet patient needs in chronic kidney disease. Int J Nephrol Renovasc Dis 2012;5:151-163.

45 Ronco C, Mason G, Nayak Karopadi A, Milburn A, Hegbrant J: Healthcare systems and chronic kidney disease: putting the patient in control. Nephrol Dial Transplant 2014;29: 958-963.

46 NIfHaCE: Renal Replacement Therapy and Conservative Management, 2018. https:// www.nice.org.uk/guidance/ng107 (October $28,2018)$. 
47 Icks A, Haastert B, Gandjour A, Chernyak N, Rathmann W, Giani G, et al: Costs of dialysisa regional population-based analysis. Nephrol Dial Transplant 2010;25:1647-1652.

48 Neild GH: Life expectancy with chronic kidney disease: an educational review. Pediatr Nephrol 2017;32:243-248.

49 Wang V, Vilme H, Maciejewski ML, Boulware LE: The economic burden of chronic kidney disease and end-stage renal disease. Semin Nephrol 2016;36:319-330.

50 Gliklich RE, Dreyer NA, Leavy MB: Registries for Evaluating Patient Outcomes: A User's Guide (ed. 3). Rockville, Agency for Healthcare Research and Quality (US), 2014.

51 Zorgkaart Nederland. Wat is Zorgkaart Nederland, 2017. https://www.zorgkaartnederland.nl/content/wat-is-zorgkaartnederland (August 17, 2017).

52 Rijksoverheid. De juiste zorg op de juiste plek. Wie durft? 2018. https://www.rijksoverheid. nl/binaries/rijksoverheid/documenten/rapporten/2018/04/06/de-juiste-zorg-op-dejuiste-plek/de-juiste-zorg-op-de-juiste-plek. pdf.

53 European Renal Association - European Dialysis and Transplant Association (ERA-EDTA). ERA-EDTA Registry, 2017. https:// www.era-edta-reg.org/index.jsp? $\mathrm{p}=1 \quad(\mathrm{Au}-$ gust 17, 2017).

54 European Renal Association - European Dialysis and Transplant Association (ERA-EDTA) ERA-EDTA Registry: Data Collection, 2017. https://www.era-edta-reg.org/index.jsp?p=7 (August 17, 2017).

55 European Renal Best Practice (ERBP) Guidelines, 2018. http://www.european-renal-bestpractice.org/content/ebpg-european-bestpractice-guidelines-documents\#overlay-context $=$.

56 Bikbov B, Bieber B, Andrusev A, Tomilina N, Zemchenkov A, Zhao J, et al: Hemodialysis practice patterns in the Russia dialysis outcomes and practice patterns study (DOPPS), with international comparisons. Hemodial Int 2017;21:393-408.

57 Ouwens M, Wollersheim H, Hermens R, Hulscher M, Grol R: Integrated care programmes for chronically ill patients: a review of systematic reviews. Int J Qual Health Care 2005; 17:141-146.

58 Hommel K, Madsen M, Kamper AL: The importance of early referral for the treatment of chronic kidney disease: a Danish nationwide cohort study. BMC Nephrol 2012;13: 108.

59 García García M, Valenzuela Mújica MP, Martínez Ocaña JC, Otero López Mdel S, Ponz Clemente E, López Alba T, et al: Results of a coordination and shared clinical information programme between primary care and nephrology. Nefrologia 2011;31: 84-90.

60 Johnson DS, Kapoian T, Taylor R, Meyer KB: Going upstream: coordination to improve CKD care. Semin Dial 2016;29:125-134.
61 Sultan J, Matthews M: Blueprint for Bundled Payments: Strategies for payors and providers; in Donovan P, Miller C, Salmon J (eds): Guide to Value-Based Reimbursement: Profiting from Payment Bundling, PHO Shared Savings, and Pay for Performance. Sea Girt, The Healthcare Intelligence Network, 2013, pp 8-34

62 Berenson RA, Upadhyay DK, Delbanco SF, Murray R: Payment Methods and Benefit Designs: How They Work and How They Work Together to Improve Health Care. URBAN Institute, 2016.

63 Wilensky GR, Wolter N, Fischer MM: Gain sharing: a good concept getting a bad name? Health Aff (Millwood) 2007;26:w58-w67.

64 Ponce P, Marcelli D, Guerreiro A, Grassmann A, Gonçalves C, Scatizzi L, et al: Converting to a capitation system for dialysis payment the Portuguese experience. Blood Purif 2012; 34:313-324.

65 Coelho AP, Sá HO, Diniz JA, Dussault G: The integrated management for renal replacement therapy in Portugal. Hemodial Int 2014; 18:175-184.

66 Jones ER, Hostetter TH: Integrated renal care: are nephrologists ready for change in renal care delivery models? Clin J Am Soc Nephrol 2015;10:335-339.

67 Valentijn PP, Biermann C, Bruijnzeels MA: Value-based integrated (renal) care: setting a development agenda for research and implementation strategies. BMC Health Serv Res 2016;16:330. 